\title{
Compressive strength of heterogeneous masonry walls containing blends of brick types
}

\author{
Andrea Benedetti (i) - Mirco Tarozzi
}

Received: 3 September 2021 / Accepted: 11 February 2022/Published online: 24 February 2022

(C) The Author(s) 2022

\begin{abstract}
The study presents a systematic approach for the evaluation of the compression strength of masonry walls composed of heterogeneous mixes of different types of blocks. First of all, the mechanics of a compressed heterogeneous masonry stack is investigated through a series of experimental tests and Finite Element models, then it is reviewed and discussed. Then, the problem of deriving the necessary material parameters entering the Hilsdorf formula is addressed. Solutions for the correct evaluation of the lacking data are presented based on the existing literature data. Finally, the well-known Hilsdorf formula is extended to the field of block blends with different mechanical properties. A deep experimental investigation on stacks and wallets made with fired clay, limestone and sandstone blocks is introduced for the first time. The comparison of the experimental data with the proposed theory points out the very good
\end{abstract}

In honour of Professor Piero Pozzati, a master among the founders of structural engineering in Italy, in the centennial of the birth (1922-2015).

Supplementary Information The online version contains supplementary material available at https://doi.org/10.1617/ s11527-022-01912-0.

A. Benedetti $(\bowtie) \cdot$ M. Tarozzi

Department of Civil, Chemical, Environmental and Materials Engineering, University of Bologna, Viale Risorgimento 2, 40136 Bologna, Italy

e-mail: andrea.benedetti@unibo.it predictive capability of the extended Hilsdorf formula derived herein.

Keywords Masonry - Brick blends - Compressive strength $\cdot$ Hilsdorf formula $\cdot$ Poisson ratio $\cdot$ MohrCoulomb plasticity

\section{Introduction}

The knowledge of the mechanical properties of an existing building is at the base of its structural assessment. Especially for masonry structures, several models have been developed over the years trying to predict their global capacity. The technological improvement of the last twenty years led to the development of sophisticated numerical models that needs a large computational time to provide the problem solution. Besides, sometimes it happens that even no convergence or mindless results could be achieved. Both numerical and analytical models are often supported by experimental tests, which can prove the accuracy of the proposed model. Lofti et al. [1] and Lourenco et al. [2] reproduced numerically the behaviour of a masonry panel considering the exact geometry of both components by introducing the concept of the interface model. However, the method is nowadays far from practical use when a large number of units is involved. A few years later, 
Zucchini and Lourenco [3] discussed several existing results concerning methods for masonry homogenization and validated experimentally their micro-mechanical model based on Representative Volume Elements.

On the other hand, formulas and relations could be even found experimentally from the observation of the physical behaviour and regression analysis of the data sets. Recently, Ferretti [4] calibrated a dimensionless power model for predicting the compressive strength of solid-clay-brick masonry walls by collecting a large base of data from the available literature in which both stacks and wallets were included. The calibration of the model involving dimensionless parameters extended the formula proposed by the EC6 [5] to more general instances made of units of only one material. However, it is to stress that, unlike some nonEuropean studies, the largest effort has been put in masonry systems in which the mortar is weaker than units, and therefore in the present study cases with strong mortar and weak units will be disregarded, although the proposed theory applies in principle even to those sets.

Concerning the compressive strength of a layered stack composed of two alternating materials, it has been widely studied since the beginning of the twentieth century (for a list of contributions see Proske and Van Gelders [6]). The solution introduced in 1969 by Hilsdorf [7] and partially described earlier in a work of Haller in 1958 [8], based on the study of the mutual horizontal stress under vertical compressive loading, answers the question: "Why does a stack of two materials fail under compression at a stress larger than the minimum compressive strength of the two materials?" A detailed discussion of the compressive strength of brick and mortar stacks can be found in Aprile et al. [9] and Como [10]. The equilibrium and compatibility equations are:

$\sigma_{v m}=\sigma_{v b}=\sigma_{v}, \sigma_{h b} t_{b}=-k \sigma_{h m} t_{m}, \varepsilon_{h m}=\varepsilon_{h b}$

where the subscript $v$ and $h$ stand for the vertical and horizontal directions, $b$ is for bricks, $m$ is for mortar, and $t$ is the thickness of the material layers. In the case of masonry wallets (Fig. 1A), the horizontal direction is affected by the presence of the head joints. These weak elements increase the tensile stress required on bricks for fulfilling the equilibrium with the compressed mortar layers, compared to the case of masonry stacks (Fig. 1B). The resulting stress increment is roughly proportional to the number of mortar layers that interact with each brick. Therefore an influence factor $k$ ( $k=2$ for wallets and $k=1$ in the case of stacks) is added in the formula (1) stating the horizontal equilibrium.

The solution of the problem gives the ratio of the horizontal and vertical stresses:

$$
\begin{aligned}
\sigma_{h m} & =\frac{v_{m}-v_{b} \rho}{1-v_{m}+\left(1-v_{b}\right) \frac{k}{\rho} \eta} \sigma_{v}=\Phi \sigma_{v}, \sigma_{h b} \\
& =-k \eta \sigma_{h m}
\end{aligned}
$$

In which $v$ is the Poisson ratio, $\rho$ is the ratio of the elastic moduli $E_{m} / E_{b}$ and $\eta$ is the ratio of the thicknesses $t_{m} / t_{b}$. Finally, the masonry compressive strength can be computed through the Mohr-Coulomb criterion:

$f_{c M}=\left(\frac{1}{f_{c b}}+\frac{\Phi k \eta}{f_{t b}}\right)^{-1}$

where the subscript $M$ stands for masonry and $f_{c b}$ and $f_{t b}$ are the compressive and tensile strengths of bricks. The collapse is produced by vertical cracks running on the blocks whilst the mortar is in a triaxial compression state, which maintains it in an elastic range well beyond the uniaxial compressive strength [11]. Several studies [12-16] have demonstrated that a proportional loading with confinement stresses of $30-40 \%$ of the vertical compressive stress, can allow cement mortars to raise stresses over 10 times the uniaxial strength.

However, real ancient masonry panels include normally several types of bricks, due to the reuse of demolition parts of other buildings. Stonemasonry walls include often layers of fired clay bricks [10]. Even adobe brick walls show inclusions of fired bricks, mainly on the lower storeys or around the openings. It is thus necessary to understand what is the compressive capacity of a wall containing brick blends.

A first experimental and theoretical study was presented in Benedetti [17], in which tests conducted on model wallets made with mixed adobe and fired bricks were presented and analysed. Afterwards, several experiments were performed at the University of Firenze [18, 19] by mixing three different types of materials (namely fired bricks, limestone and sandstone blocks), but the relevant interpretation theory was not set out.

In what follows the experiments are reconsidered and a general theory able to interpret the behaviour of 

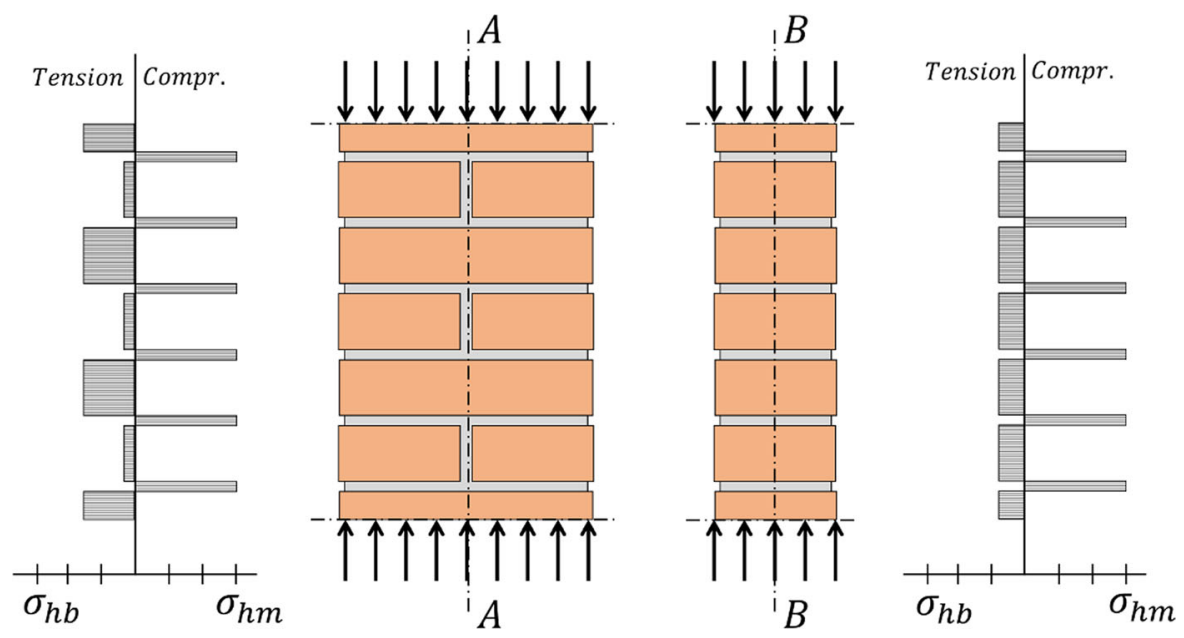

Fig. 1 Horizontal stress distribution along the vertical direction for wallets (A) and stacks (B)

walls with general brick admixtures is presented and verified against the experimental data.

\subsection{Outline of the study, objective and original contribution}

The research is based on the following steps:

(1) Definition of the material parameters and the type of analysis relevant for the problem under study,

(2) Presentation of the experimental results of two wide investigations on the compressive strength of masonry stacks and wallets including brick admixtures,

(3) Set up of the Hilsdorf Extended Theory (HET) and its verification against the presented experimental data.

This work wants to provide an analytical tool for a rapid and direct evaluation of the strength of heterogeneous masonry walls. Assorted brick materials and their random position in the same wall are typical of old masonry buildings for which the manufacturing followed the local availability of the materials, especially after exceptional events, like earthquakes or floods, when the reconstruction needs to be fast for restoring the normal life quickly. The local behaviour of blended masonry observed in some specimens can be extended to existing blended walls explaining local failures or estimating their mechanical properties having the wall pattern.
Most of the experimental studies presented in the literature use only a reduced set of mechanical parameters for mortars and bricks. Therefore the first contribution of this study is aimed at introducing rules for the derivation of the missing data and the selection of the structural problem type.

Then, the second contribution is the extension of the Hilsdorf formula to general compositions of bricks with different properties and dimensions. In most of the numerical benchmark and case history analyses present in the literature, the masonry properties are assumed constant over the whole structure, and sometimes extracted by similarity from other studies. The proposed approach fills the gap of finding homogenized materials' properties to be assigned to local elements in most of the mesoscale and large scale numerical models built for a close structural assessment of real heterogeneous structures. However, to maintain the study relevant for practical applications, in this first derivation, the effect of the wall spatial organization and brick clustering is introduced through the scalar influence factor $k$ introduced in Eq. (2), which involves only the number of mortar courses interacting with each bricklayer. 


\section{Parameters influencing the brick-mortar interaction problem}

\subsection{Definition of the elastic interaction problem}

Masonry walls can be organised with many different bonding patterns, which in principle could produce varying levels of mortar confinement, but in any case, a set of parallel stacks can be identified in every wall. Therefore, even if the problem is intrinsically $3 \mathrm{D}$, it can be studied as a 2D problem either for in-plane stress or in-plane strain condition.

A detailed elastic study has been worked out, assuming perfect bonding between brick and mortar layers, for a 2D infinite masonry stack and a 3D crossing bond column of the same size. Since the problem is assumed linear elastic, no interface constitutive laws were considered for the connection zones of the different material layers. The used material data are:

- Brick: $E_{b}=10,000 \mathrm{MPa}, v_{b}=0.125, h_{b}=60 \mathrm{~mm}$

- Mortar: $E_{m}=2000 \mathrm{MPa}, \quad v_{m}=0.250$, $h_{m}=15 \mathrm{~mm}$

In Fig. 2 the Finite Element Models used in this study are presented, in which a quarter of a 3D column with a section of $250.250 \mathrm{~mm}^{2}$ has been modelled, together with the equivalent 2D stack of the same size. Concerning the 3D model, 8-nodes solid brick elements were used either for mortar or masonry units, while 4-nodes elements were chosen in the case of the 2D FE model, leading to the linear description of the stresses as the best compromise between the model accuracy and the computational cost. In detail, 3 and 12 solid bricks layers are used for modelling the thickness of mortar and brick courses in the 3D model, while 24 and 5 plane elements layers are used in the 2D model. Both models were created by using the Italian release of the STRAND Finite Element software. Figure 3 shows the comparison among the horizontal stresses obtained in 3D, 2D plane stress and 2D plane strain models under the same unitary load pressure equal to $1 \mathrm{MPa}$ at the top and the bottom of the stacks. Since the two models are self-balanced along with the vertical direction, only lateral restraints have been considered. In particular, the $2 \mathrm{D}$ mesh is a subset of an infinite stack with a whole model width of $250 \mathrm{~mm}$, and a thickness of $250 \mathrm{~mm}$. The restraints simply eliminate the possible rigid body motions of the 2D displacement field. The 3D model is split by the two symmetry planes and includes, in addition to the restraints eliminating the rigid body motions, the horizontal restraints forcing a zero displacement across those planes.

As is fairly evident, the $3 \mathrm{D}$ and $2 \mathrm{D}$ plane strain analyses match very well, while $2 \mathrm{D}$ plane stress has a large error in the mortar confinement estimation. This result is well documented in the literature [20]. Therefore, in the study of the interaction in brick blends a 2D plane strain analysis will be carried out.

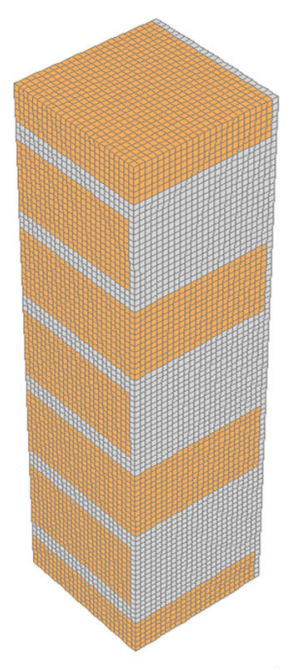

(a)
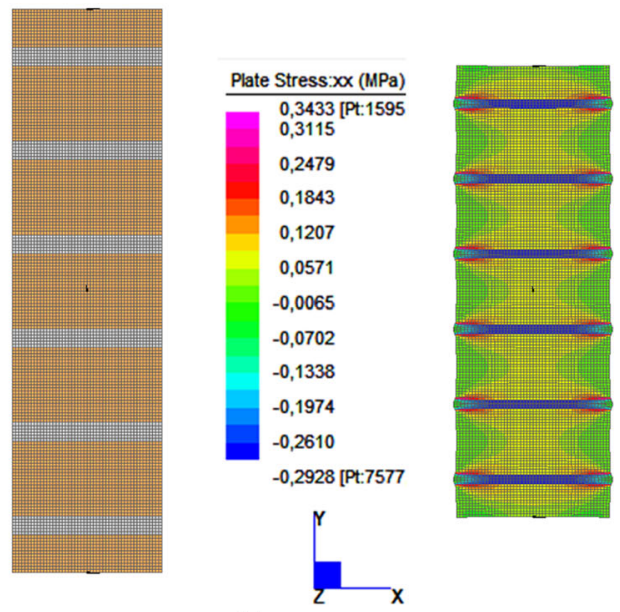

(b)

Fig. 2 View of the FEM models for 3D and 2D elastic interaction analyses 


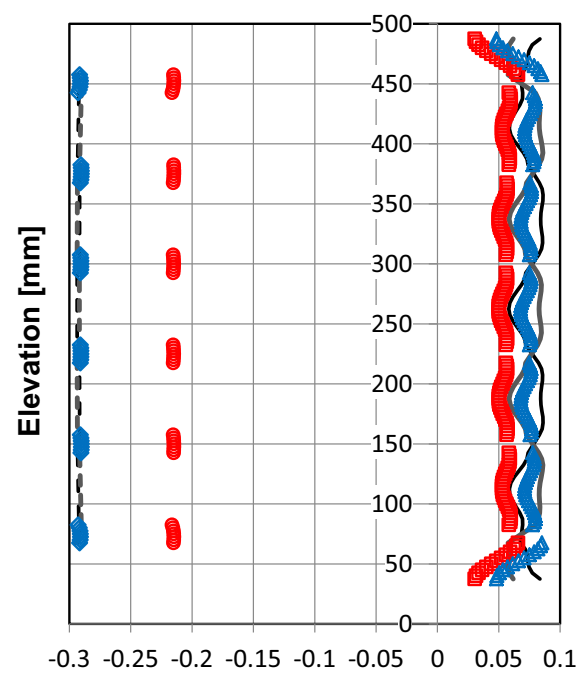

Horizontal stress ratio [-]

\begin{tabular}{|c|c|c|c|}
\hline 0 & Mortar Plane Stress & $\square$ & Brick Plane Stress \\
\hline$\diamond$ & Mortar Plane Strain & $\Delta$ & Brick Plane Strain \\
\hline \multirow{2}{*}{\multicolumn{2}{|c|}{$\begin{array}{l}\text { - - Mortar 3D - XX } \\
- \text { - - Mortar 3D - ZZ }\end{array}$}} & & Brick 3D - XX \\
\hline & & & Brick 3D - ZZ \\
\hline
\end{tabular}

Fig. 3 Stress ratios of brick and mortar for the three examined models (plain strain, plain stress, and solid)

\subsection{Extracting the missing material parameters}

The definition of compressive strength for stacks of brick blends requires not only a precise knowledge of the compressive and tensile strength of the involved bricks but also representative values of mortar and brick Poisson's ratios, very elusive and difficult to be measured experimentally.

Concerning the tensile strength of the bricks, it is to cite that at least three different values can be obtained from laboratory tests, namely flexural, splitting, or direct tensile strengths. Thus, conversion rules are necessary, since the flexural strength is larger than the uniaxial tensile strength, while the splitting strength is smaller.

The flexural strength depends on the shape of the specimen, but generally, its value is $50 \%$ above the uniaxial tensile strength. Regarding the splitting strength $f_{t, s p}$, by assuming a ratio $z$ of the vertical to horizontal stresses in the cylinders subject to splitting, a Mohr-Coulomb criterion can allow defining the strength conversion [21]:

$f_{t}=\frac{f_{c} f_{t, s p}}{f_{c}-z \cdot f_{t, s p}}$
According to $\mathrm{Li}$ [22], the factor $z$ can be computed in the centre of the cylinder as a function of the loading arc opening $\theta$, normally resulting in values very near to 3.0 :

$z=\frac{\sin 2 \theta+\theta}{\sin 2 \theta-\theta}$

However, in many studies, the tensile strength of bricks is not even taken into consideration, though it is fundamental for a Mohr-Coulomb analysis. Many studies can be found in the literature dealing with the ratio of tensile to compressive uniaxial strength of mortars, bricks and stones [23, 24]. A wide and detailed analysis of experimental data led to defining a very typical functional form that links the two strengths:

$f_{t}=\alpha f_{c}^{\beta}$

Usually, the coefficient $\alpha$ seems to vary with the material type (lime mortar, concrete, brick, stone, etc.), the coefficient $\beta$ is almost constant among materials and holds $2 / 3$ [25].

As an example, in the following Table 1 the specimens' geometry and the results of an experimental campaign, done in Forlì, Italy [26] on XVII century bricks, are presented. In particular, two specimens were collected for each brick of interest: a solid prism was cut from the original brick and then tested in compression evaluating its compressive capacity $f_{c}$, while a brick core was drilled from the same unit estimating its tensile strength through the splitting test $f_{s p}$. The compressive and splitting strength are used in defining the pure tensile strength of the brick as in formula (4). Then this value is compared with formula (6). The agreement between the two values is noticeable.

The evaluation of the Poisson ratio is problematic by either using experimental data or looking at the results of mechanical theories. A deep and detailed discussion of the importance and the criteria for the evaluation of this parameter can be found in rock mechanics contributions [16, 27]. Zhang presented in Chinese [28] a detailed discussion of the relationship of the Coulomb friction angle $\phi$, the rigidity $R$ and the Poisson ratio $v$, which was later reconsidered by Logo [29]. It is to point out that the rigidity ratio has values fairly equal to the Hoeck-Brown constant $m_{i}$ [30]: 
Table 1 Geometry and strengths of the old bricks tested in Forlì [26]

\begin{tabular}{|c|c|c|c|c|c|c|c|c|c|}
\hline \multirow[t]{2}{*}{ Specimen } & \multicolumn{3}{|c|}{ Prisms compressive test } & \multicolumn{3}{|c|}{ Cores brazilian test } & \multicolumn{3}{|c|}{ Brick tensile strength } \\
\hline & $\begin{array}{l}\text { Length } \\
{[\mathrm{mm}]}\end{array}$ & $\begin{array}{l}\text { Height } \\
{[\mathrm{mm}]}\end{array}$ & $\begin{array}{l}f_{c} \\
{[\mathrm{MPa}]}\end{array}$ & $\begin{array}{l}\text { Diameter } \\
{[\mathrm{mm}]}\end{array}$ & $\begin{array}{l}\text { Length } \\
{[\mathrm{mm}]}\end{array}$ & $\begin{array}{l}f_{s p} \\
{[\mathrm{MPa}]}\end{array}$ & $\begin{array}{l}f_{t}^{\mathrm{a}} \\
{[\mathrm{MPa}]}\end{array}$ & $\begin{array}{l}f_{t}^{\mathrm{b}} \\
{[\mathrm{MPa}]}\end{array}$ & $\begin{array}{l}\text { Error }[-] \\
(\%)\end{array}$ \\
\hline A4 & 41 & 82 & 30.40 & 75 & 90 & 1.86 & 2.28 & 2.44 & -6 \\
\hline B4-1 & 45 & 90 & 23.05 & 44 & 70 & 1.60 & 2.02 & 2.02 & 0 \\
\hline B4-2 & 45 & 90 & 32.93 & 44 & 44 & 2.83 & 3.81 & 2.57 & 48 \\
\hline $\mathrm{C} 2-2$ & 45 & 90 & 39.93 & 44 & 44 & 2.64 & 3.29 & 2.92 & 13 \\
\hline $\mathrm{C} 5$ & 37 & 81 & 26.36 & 75 & 85 & 1.76 & 2.20 & 2.21 & -1 \\
\hline C6 & 40 & 82 & 25.47 & 75 & 90 & 1.51 & 1.84 & 2.16 & -15 \\
\hline D1 & 43 & 75 & 30.64 & 44 & 54 & 1.86 & 2.27 & 2.45 & -7 \\
\hline D2 & 36 & 71 & 28.53 & 44 & 77 & 1.30 & 1.51 & 2.33 & -35 \\
\hline D4-2 & 37 & 80 & 37.82 & 44 & 80 & 2.40 & 2.96 & 2.82 & 5 \\
\hline E1 & 44 & 86 & 21.82 & 44 & 80 & 1.28 & 1.55 & 1.95 & -20 \\
\hline F1 & 41 & 80 & 35.52 & 44 & 73 & 2.50 & 3.17 & 2.70 & 17 \\
\hline G2 & 38 & 81 & 32.08 & 75 & 85 & 1.84 & 2.22 & 2.52 & -12 \\
\hline
\end{tabular}

${ }^{\text {a }}$ The value is computed with formula (4) by using $z=3$

${ }^{\mathrm{b}}$ The value is computed by using formula (6) with $\alpha=0.25$

$R=m_{i}=\frac{f_{c}}{f_{t}}=\frac{1+\sin \phi}{1-\sin \phi}$

Anson and Newman [31] discussed the difference between Poisson ratio values obtained through static and dynamic experiments and the effect of the porosity on the detected values. In fact, tensile and compressive strengths, elastic moduli and Poisson ratio are all approximately inversely proportional to the porosity of the material.

It is well known that in uniaxial compression tests the Poisson ratio (measured as the ratio of the horizontal to the vertical strains), is weakly decreasing in the elastic range, and then is rapidly increasing with the onset of the microcracking, finally even overpassing the limit value 0.5 near the collapse [21, 32].

However, as discussed before, the masonry mortar courses are mainly in a triaxial compression state in which microcracking is hindered so that the Poisson ratio has only marginal variations with the confinement ratio [15, 33].

Therefore, since the mortar-brick interaction is effective until the cracking of bricks or the crushing of mortar, it is natural to assume that the Poisson ratio is holding constant in this pre-failure range, and its value is linked (through porosity) to the strength ratio $R$.
In particular, the Poisson ratio can be obtained by the following approximations [29]:

$v=\left\{\frac{1}{2 \sqrt{R}}, \frac{1}{1+\sqrt{R}}, \frac{2}{R+3}, \frac{4 R}{1+6 R+R^{2}}\right\}$

$(8, a, b, c, d)$

The proposed formulas are compared with some literature experimental values in Fig. 4 [31-36].

Equation $(8 b, c)$ give values that better represent the behaviour detected with the experiments.

Therefore, even when only the compressive strength is known, it is possible to gather the complete set of brick and mortar parameters by the following procedure:

(a) The tension strength is evaluated from splitting tests or by using Eq. (6);

(b) The Coulomb friction angle is determined from the ratio $R$;

(c) The Poisson ratio is obtained from Eq. (8b).

Finally, once the $\Phi$ factor is computed, the compressive strength of masonry is obtained via the Hilsdorf theory. 
Fig. 4 Poisson Ratio as a function of the friction angle Eq. (8) (a) and the comparison with experimental values in [31-36] (b)

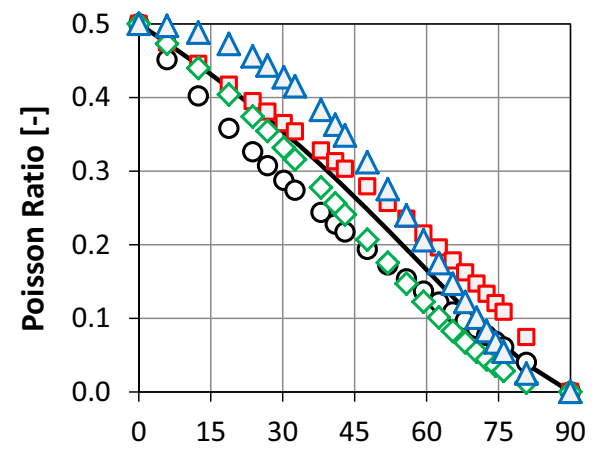

(a)

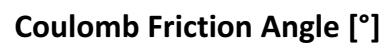

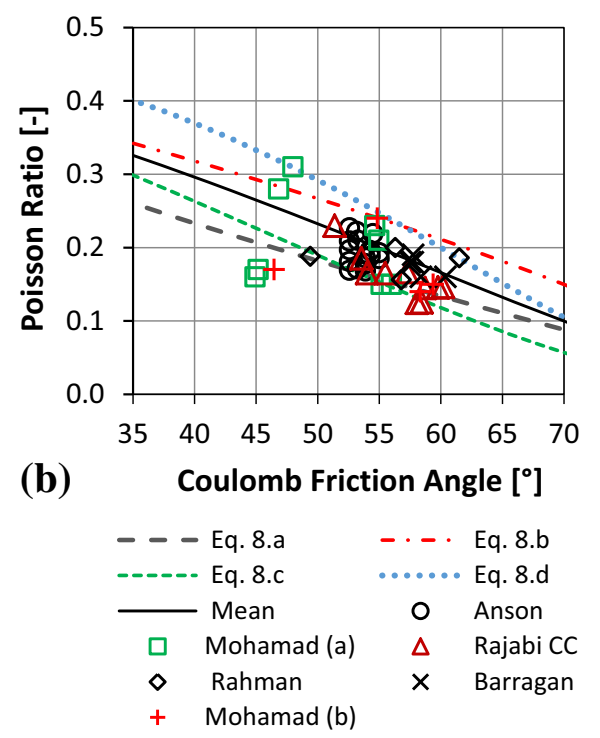

\section{Elastic analysis of heterogeneous masonry stacks}

A masonry stack composed of a blend of different bricks is neither a random material nor a regularly layered composite. It is thus significant to examine horizontal stress values arising from the interaction of mortar with blends of different bricks, which can lay either as staggered clusters or in interspersed sequences.

In what follows, according to the previous results of the finite element investigations, several plane strain stacks composed of ten courses of three typical brick materials will be investigated. The mechanical properties are chosen, on average, according to Augenti et al. [37]:

(a) Mortar: $E_{m}=2000 \mathrm{MPa}, v_{m}=0.250$

(b) Fired clay bricks: $E_{c}=10,000 \mathrm{MPa}, v_{c}=0.125$

(c) Limestone bricks: $E_{l}=4000 \mathrm{MPa}, v_{l}=0.175$

(d) Sandstone bricks: $E_{s}=25,000 \mathrm{MPa}$, $v_{s}=0.075$

The selected thickness of the layers produces two $\eta$ values, namely 0.364 (blocks $55 \mathrm{~mm}$, mortar $20 \mathrm{~mm}$ ), and 0.25 (blocks $60 \mathrm{~mm}$, mortar $15 \mathrm{~mm}$ ). In the following Fig. 5, the stacks are presented.

The nomenclature is as follows: $A$ stands for alternate units and $B$ for clustered sets (sequence of clusters of the same brick type), $C$ for clay units, $L$ for limestone units and $S$ for sandstone units. The number is the percentage of every material composing the stack, 2.75 and 4.00 are the unit/mortar thickness ratios used for the simulation.

Even some compositions of three materials were examined. In Fig. 5d the three studied sample block sequences are listed.

Since the bonding pattern could be different according to the content of different bricks and their position, the analysis of any possible combination is not achievable. Therefore, considering alternated and clustered brick distributions as the two limit bounds of all the possible configurations, other layouts are surely included in the study.

The analysis was carried out as plane strain on finite element models with unitary vertical stress. The models were composed of 4000-7000 square fournode finite elements with a side of $5 \mathrm{~mm}$ belonging to the whole model side of $120 \mathrm{~mm}$, and then the symmetry conditions were set at the two end faces.

To compare the horizontal stress in mortar courses and different brick materials, the stress values at the symmetry plane of the stacks were extracted from the models. However, due to the local combinations of block types, the horizontal stresses are mildly varying among different mortar and block positions, and even in different layers of the same course.

Therefore average stress values were obtained by summing up the stress resultants for every material and dividing it by the given material area crossing the symmetry plane. 
Fig. 5 The layouts of the investigated stacks

$($ Red = Clay,

Yellow = Limestone,

Blue $=$ Sandstone $)$. (Color figure online) (a)

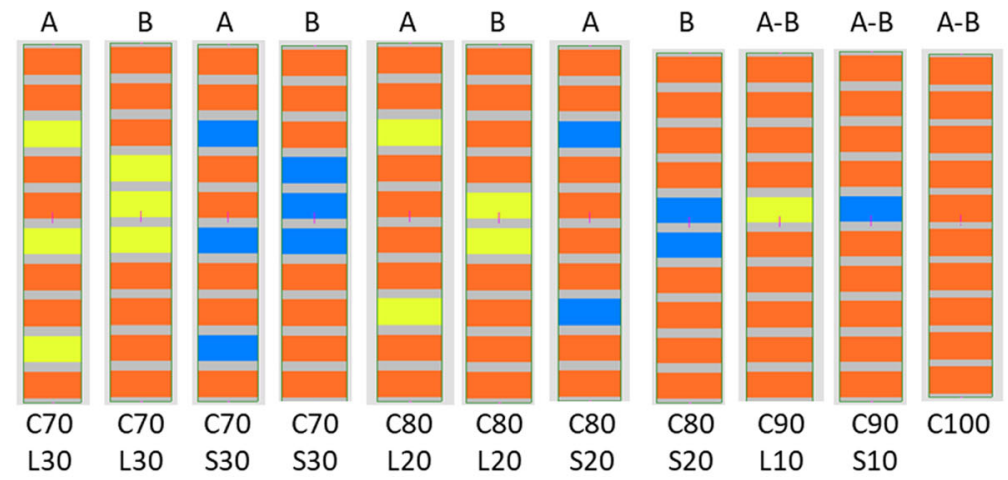

(b)

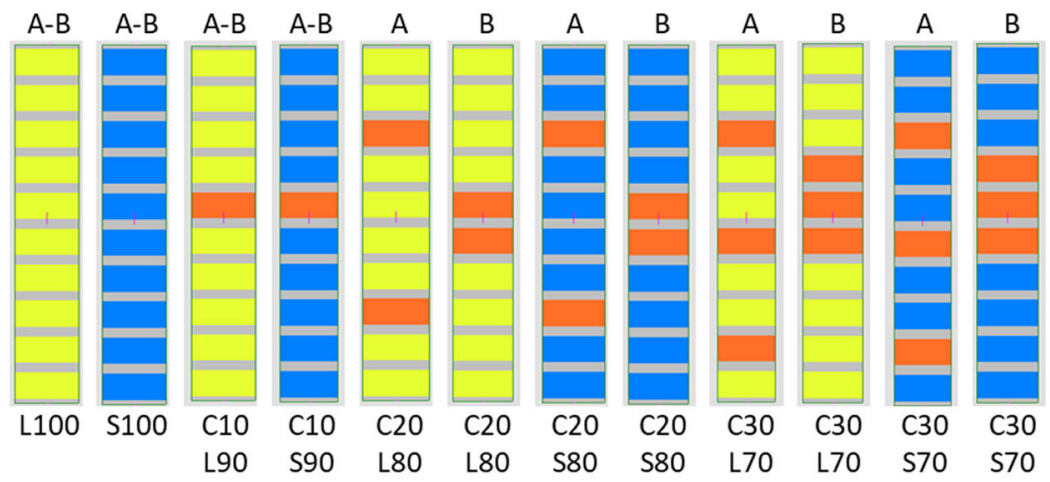

(c)

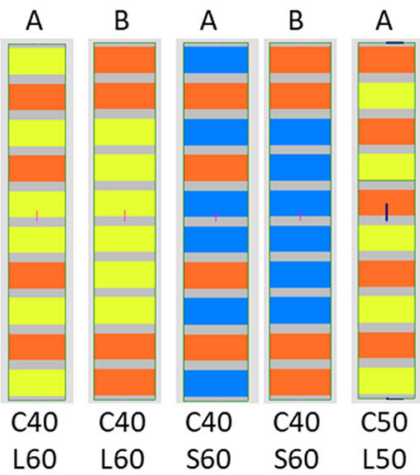

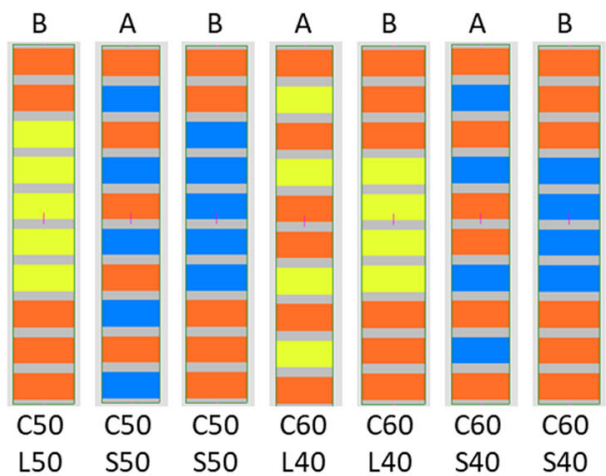

(d)

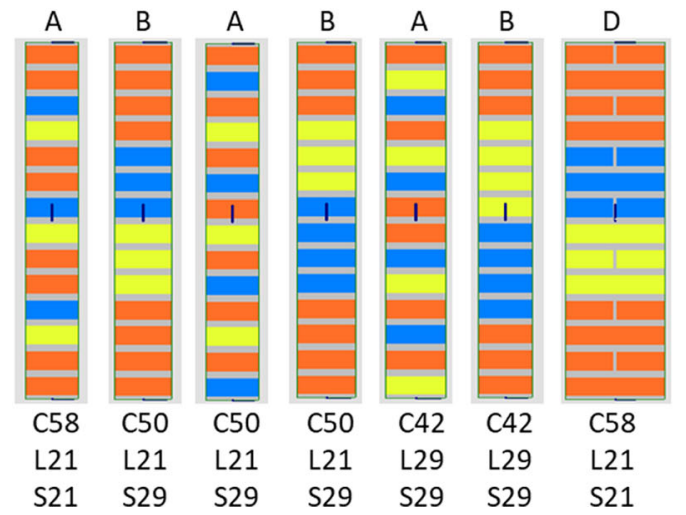

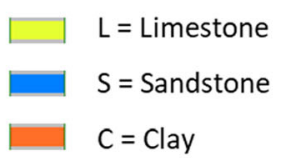

$A=$ Alternate

$B=$ Clustered 
The effectiveness of the averaging procedure has been checked by computing the equilibrium on the symmetry plane of the stress resultants of the different material groups. A fairly good error of less than $0.1 \%$ of the tension and compression resultants has been obtained.

The following Fig. 6a, b present the results for the mortar horizontal stress and the clay brick horizontal stress, as it is computed in the various models by varying the sandostone or limestone content and the ratio $h=t_{b} / t_{m}$. Given the stresses from the FE model, the adimensional stress ratios are then obtained by dividing by $1 \mathrm{MPa}$ as a reference stress value.

The numerical results clearly point out that the mortar horizontal confinement stress $\sigma_{h m}$ is approximately independent of the bond layout of the stacks, while the average stiffness of the blocks, given as the homogenized elastic modulus of the components through their volumetric ratios, is resulting in a linear influence on it. Thus, since clay is stiffer than limestone but softer than sandstone, the two diagrams of Fig. 6a show respectively ascending and descending paths with the increase in brick content. On the other hand, the brick tensile stress $\sigma_{h b}$ is depending strongly on both the bonding pattern and the thickness ratio $h$, even if the stress ratios are contained in a narrower range.

Since the collapse of masonry is mainly linked to the combined compressive-tensile biaxial stress of the blocks, obtaining a well-approximated evaluation formula for the block horizontal stress is an important task.
The performed numerical experiments point out that the mortar stress ratio $\Phi$ is strongly dependent on the homogenized properties of the block blend, while the block distribution has almost no influence. Therefore it is a realistic assumption that the collapse of a heterogeneous panel will be driven by the averaged equilibrium of the horizontal stresses in the elastic range until a diffused cracking of the blocks will affect the local stability of the separated stacks, leading to failure.

Therefore, in the following, the extended HallerHilsdorf theory (HET) will be discussed and verified avoiding any complex non-linear numerical simulation and considering only an elastic-brittle behaviour for the bricks. The proposed extension of the theory and the procedure for the statement of the missing parameters will be verified against experimental results of masonry panels realized with both homogeneous and heterogeneous blended block systems.

\section{Experimental compressive strength of wallets with blended blocks}

In what follows, the results of a large experimental investigation carried out at the University of Firenze is discussed [18, 19]. The results concern mainly the compressive strength of scaled-down stacks and wallets (Figs. 7 and 8) composed of fired clay bricks $(C)$ and units sawn from lime- $(L)$ and sandstone $(S)$ blocks. The mortar used for building each stack is a weak lime mortar according to what is typically present in historical constructions.
Fig. 6 Mortar (a) and Clay brick (b) horizontal stress ratio over the clay brick content found using finite element models

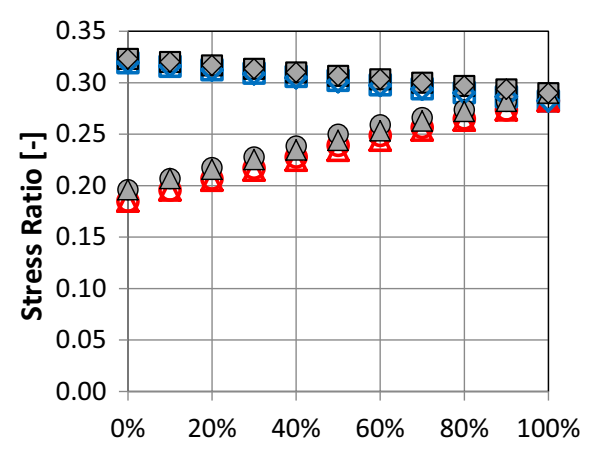

(a)

Clay brick content [\%]

(b)

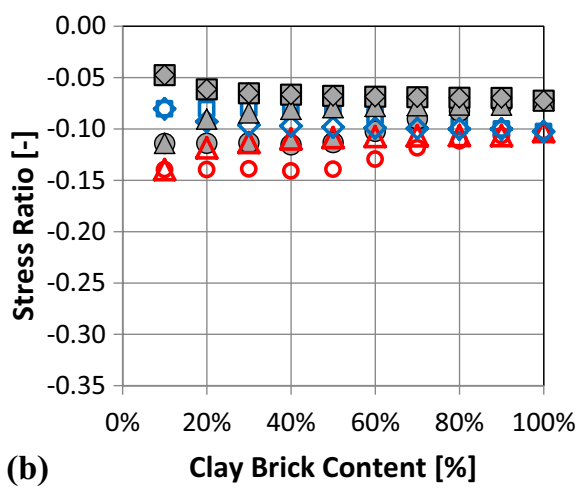

O L. Alternated, $\mathrm{h}=2.75 \square \mathrm{S}$. Alternated, $\mathrm{h}=2.75$

$\Delta \mathrm{L}$. Banded, $\mathrm{h}=2.75 \quad \diamond \mathrm{S}$. Banded, $\mathrm{h}=2.75$

L. Alternated, $\mathrm{h}=4.00$

S. Alternated, $h=4.00$

$\triangle$ L. Banded, $h=4.00$

$\diamond \mathrm{S}$. Banded, $\mathrm{h}=4.00$ 

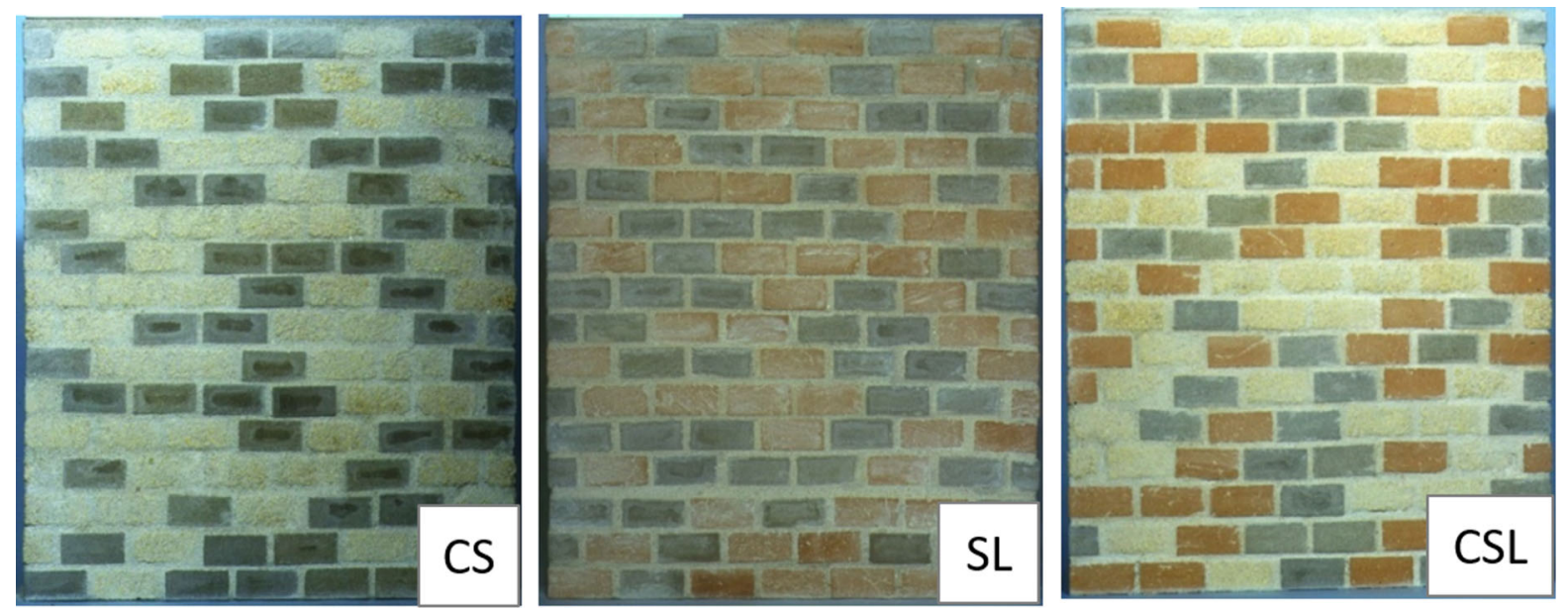

Fig. 7 View of the Clay-Sandstone (CS), Sandstone-Limestone (SL) and Clay-Sandstone-Limestone (CLS) panels
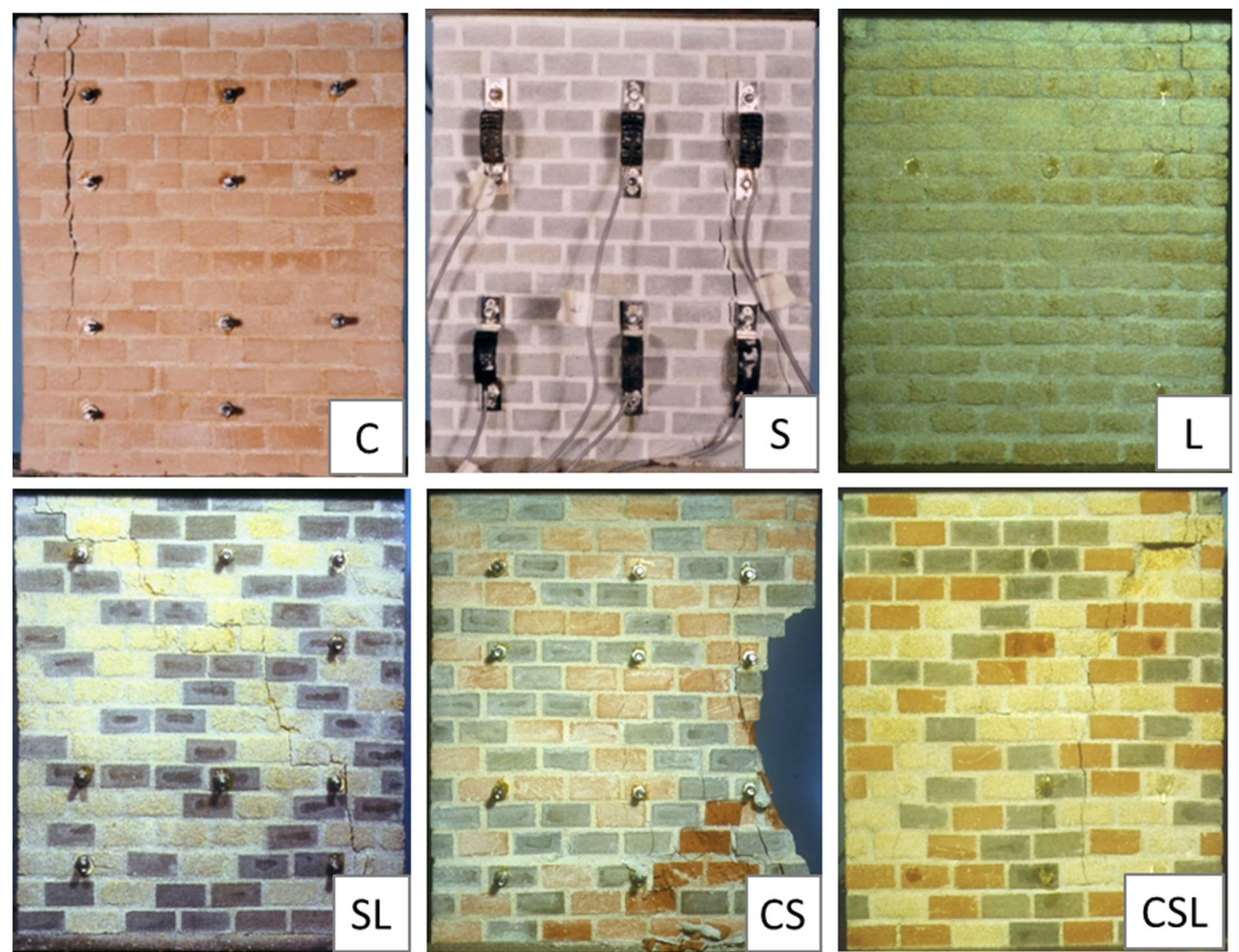

Fig. 8 View of the Clay $(C)$, Sandstone $(S)$, Limestone $(L)$, Clay-Sandstone (CS), Sandstone-Limestone (SL) and Clay-SandstoneLimestone (CSL)panels at the end of the tests 
The stacks were composed of 6 blocks of $30 \cdot 30 \cdot 14 \mathrm{~mm}^{3}$ sawn bricks, and 7 layers of mortar of $2.5 \mathrm{~mm}$ thickness, obtaining thus scaled down 1:4 models of half brick stacks.

The wallets had dimensions of $225.63 \mathrm{~mm}^{2}$ and a height of $264 \mathrm{~mm}$ and were built in a running bond pattern, with 16 layers of bricks and 17 mortar courses of $2.5 \mathrm{~mm}$ thickness. Displacement-controlled compressive tests were performed up to the panels' failure collecting the load, the four corner vertical displacements, and six vertical strains on both faces. The strains were measured by placing $\Omega$ strain gauges on each sample according to the setup illustrated in Fig. 8. Table 2 lists the mechanical data of the used materials.

In blended panels, since the block distribution can affect the results, similar panels were erected by interchanging the block type (CS-SC, CL-LC, SL-LS).

Two batches of three stacks (sets I and III, samples 1-3) and two sets of single or two wallets (sets II and IV, samples 1-2) were built and then tested in compression. The two sets III and IV aimed at completing and checking the findings of the previous series with some more combinations. The following Table 3 lists the results of the compression tests.

In what follows the theory extending the Hilsdorf formula to wallets with every blend of blocks will be presented in detail, and the comparison with the experiments will allow checking its effectiveness in predicting the strength of real walls.

Several techniques exist concerning the assessment of existing masonry walls, and usually, minor destructive tests are preferred to other methods due to their low invasiveness. For instance, Pelà et al. [38, 39] and Segura et al. [40] inferred the strength of existing walls or masonry panels by testing under compression masonry cores and stacks even considering samples with different shapes and sizes. Concerning the experimental campaign discussed in this work, while the effects of a scaling procedure on the mechanical properties can be considered negligible for pure compressive tests [41], a linear relation was found among the strengths of stacks and wallets by Thamboo et al. [42], showing a ratio near to $4 / 3$ which can be explained in term of the influence factor $k$ already introduced and discussed. Thus, direct comparisons among the results of different test setups should be done with great caution.

\section{The extended version of Hilsdorf masonry compressive strength}

Several studies have compared experimental values of masonry wall compressive strength with available prediction formulas. Drougkas [43] presented a list of literature data and tested several formulas, including the Hilsdorf one, but many of the lacking input data were simulated by analogy. Boffill [44] considered historic brickworks with low strength mortar. Even some multiple leaf wallets were tested and discussed $[45,46]$. To point out the importance of the data entering in the Hilsdorf formula, the analysis carried out by Drougkas [43] has been considered again, by deriving the missing data with the formulas proposed in this study (Online Source 1) and plotting the computed strength versus the experimental one (Fig. 9). In the cases of Running, Flemish and English bond, the ratio $k=2$ of two mortar layers for every block has been set out according to Aprile et al. [9], due to the presence of the head joints.

The new analysis is worthy of only $34 \%$ average error (coefficient of variation 1.27), while the numerical analysis of Drougkas [43] is as high as 43\% average error (coefficient of variation of 1.77). Both the analyses tend to overestimate (positive error) the
Table 2 Data of the materials used in the experimental investigation at the Firenze University [18, 19]

\begin{tabular}{|c|c|c|c|c|c|c|c|c|c|}
\hline \multirow[t]{2}{*}{ Material } & \multirow[t]{2}{*}{ Code } & \multirow[t]{2}{*}{ Test } & \multicolumn{2}{|l|}{$f_{c}$} & \multicolumn{2}{|l|}{$E$} & \multirow{2}{*}{$\begin{array}{l}f_{t, f l} \\
\text { Mean } \\
{[\mathrm{MPa}]}\end{array}$} & \multirow{2}{*}{$\begin{array}{l}f_{t} \\
\text { Eq. (6) } \\
\text { [MPa] }\end{array}$} & \multirow{2}{*}{$\begin{array}{l}v \\
\text { Eq. }(7 c) \\
{[-]}\end{array}$} \\
\hline & & & $\begin{array}{l}\text { Mean } \\
{[\mathrm{MPa}]}\end{array}$ & $\begin{array}{l}\text { St. dev } \\
\text { [MPa] }\end{array}$ & $\begin{array}{l}\text { Mean } \\
{[\mathrm{MPa}]}\end{array}$ & $\begin{array}{l}\text { St. dev } \\
\text { [MPa] }\end{array}$ & & & \\
\hline Mortar & $m$ & I-IV & 2.05 & 0.14 & 621 & 173 & 0.853 & 0.569 & 0.304 \\
\hline Clay brick & $C$ & I-IV & 16.06 & 3.45 & 3357 & 1079 & - & 1.337 & 0.133 \\
\hline Sandstone & $S$ & I-IV & 81.76 & 8.71 & 11,919 & 2321 & - & 3.955 & 0.084 \\
\hline Limestone & L1 & I-II & 3.36 & 0.95 & 758 & 174 & - & 0.471 & 0.197 \\
\hline Limestone & L2 & III-IV & 4.73 & 0.61 & 1608 & 682 & - & 0.592 & 0.182 \\
\hline
\end{tabular}


Table 3 Results of the compression tests of batches I-IV [18, 19]

\begin{tabular}{|c|c|c|c|c|c|c|c|c|c|c|c|}
\hline Test & $\begin{array}{l}\rho_{C} \\
{[-]}\end{array}$ & $\begin{array}{l}\rho_{L} \\
{[-]}\end{array}$ & $\begin{array}{l}\rho_{S} \\
{[-]}\end{array}$ & $\begin{array}{l}f_{c, 1} \\
{[\mathrm{MPa}]}\end{array}$ & $\begin{array}{l}f_{c, 2} \\
{[\mathrm{MPa}]}\end{array}$ & $\begin{array}{l}f_{c, 3} \\
{[\mathrm{MPa}]}\end{array}$ & $\begin{array}{l}E_{1} \\
{[\mathrm{MPa}]}\end{array}$ & $\begin{array}{l}E_{2} \\
{[\mathrm{MPa}]}\end{array}$ & $\begin{array}{l}E_{3} \\
{[\mathrm{MPa}]}\end{array}$ & $\begin{array}{l}f_{c, \text { mean }} \\
{[\mathrm{MPa}]}\end{array}$ & $\begin{array}{l}E_{\text {mean }} \\
{[\mathrm{MPa}]}\end{array}$ \\
\hline $\mathrm{I}-\mathrm{C}$ & 1 & 0 & 0 & 7.77 & 7.81 & 7.62 & 1403 & 1950 & 1087 & 7.73 & 1480 \\
\hline I-L & 0 & 1 & 0 & 1.92 & 2.14 & 2.07 & 287 & 614 & 504 & 2.04 & 468 \\
\hline $\mathrm{I}-\mathrm{S}$ & 0 & 0 & 1 & 50.80 & 51.00 & 40.70 & 5820 & 5187 & 3600 & 47.50 & 4869 \\
\hline I-CL & 0.5 & 0.5 & 0 & 3.23 & 2.51 & 2.64 & 1180 & 962 & 1190 & 2.79 & 1111 \\
\hline I-CS & 0.5 & 0 & 0.5 & 15.00 & 12.90 & 16.00 & 2170 & 2156 & 2282 & 14.63 & 2203 \\
\hline II-CSL & 0.55 & 0.225 & 0.225 & 3.68 & 3.53 & - & 2098 & 2245 & - & 3.61 & 2171 \\
\hline II-CSL & 0.225 & 0.55 & 0.225 & 3.04 & 2.69 & - & 1585 & 1544 & - & 2.87 & 1564 \\
\hline II-CSL & 0.225 & 0.225 & 0.55 & 5.09 & 4.81 & - & 1986 & 2426 & - & 4.95 & 2206 \\
\hline II-CSL & 0.334 & 0.333 & 0.333 & 4.08 & 4.04 & 3.36 & 1686 & 1440 & 1216 & 3.83 & 1447 \\
\hline III-C & 1 & 0 & 0 & 10.49 & 12.67 & 10.85 & 3137 & 2880 & 1774 & 11.34 & 2597 \\
\hline III-L & 0 & 1 & 0 & 2.28 & 3.12 & 4.12 & 1738 & 1995 & 1796 & 3.17 & 1843 \\
\hline III-S & 0 & 0 & 1 & 29.90 & 28.70 & 30.00 & 2725 & 2274 & 2708 & 29.53 & 2569 \\
\hline III-LS & 0 & 0.5 & 0.5 & 7.47 & 4.91 & 5.08 & 2347 & 1057 & 1383 & 5.82 & 1596 \\
\hline IV-C & 1 & 0 & 0 & 6.37 & - & - & 1915 & - & - & 6.37 & 1915 \\
\hline IV-L & 0 & 1 & 0 & 2.90 & - & - & 1357 & - & - & 2.90 & 1357 \\
\hline IV-S & 0 & 0 & 1 & 15.30 & - & - & 2176 & - & - & 15.30 & 2176 \\
\hline IV-CS & 0.5 & 0 & 0.5 & 11.50 & 9.89 & - & 2629 & 2405 & - & 10.70 & 2517 \\
\hline IV-SL & 0 & 0.5 & 0.5 & 4.94 & 4.43 & - & 2039 & 1559 & - & 4.69 & 1799 \\
\hline IV-CL & 0.5 & 0.5 & 0 & 4.67 & 4.24 & - & 1350 & 1360 & - & 4.46 & 1355 \\
\hline IV-CSL & 0.334 & 0.333 & 0.333 & 4.95 & - & - & 1852 & - & - & 4.95 & 1852 \\
\hline
\end{tabular}

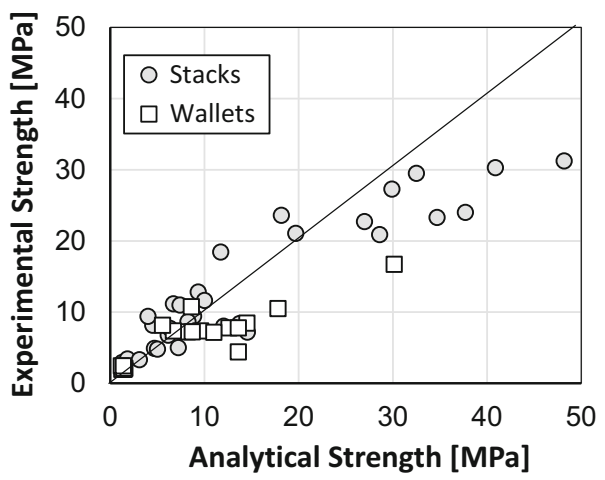

Fig. 9 Model strengths versus experimental strengths in masonry stacks and wallets (Online Source 1)

experimental strengths of the masonry stacks, but, except for a few samples with very uncommon material combinations, the use of the proposed formulas could certainly replace any complex FE analysis with reasonable accuracy.

In particular, from Fig. 9 it is apparent that the proposed formula does overestimate the resistance of weak stacks, while it is certainly on the safe side for strong stacks and wallets. The reason for this overestimation can be found in the premature collapse by crushing of the mortar layers, which is not considered in the proposed formula.

\subsection{The failure of the mortar courses}

In respect of the previous discussion, the mortar plasticization and crushing in biaxial compression rarely happens in the collapse of the masonry structure. This is consistent with the experiments of Lumantarna [47], in which several combinations of bricks and mortars have been tested on-site and in reconstructed specimens in the laboratory. The average strength of masonry stacks tested is only $65 \%$ of the uniaxial strength of blocks and $243 \%$ of the uniaxial mortar strength. A rough analytical justification can be obtained by examining the multi-axial compression failure of the mortar in light of the Coulomb criterion $[48,49]$. 
$\tau=\frac{\sigma_{v}-\sigma_{h}}{2}=c \cos \phi+\frac{\sigma_{v}+\sigma_{h}}{2} \sin \phi, \sigma_{h}=\Phi \sigma_{v}$

By using formula (7) and recognizing that:

$\frac{2 c \cos \phi}{1-\sin \phi}=f_{c}$

The following result for the failure compression is obtained:

$\sigma_{v}(\phi, \Phi)=\frac{f_{c}}{1-\Phi \cdot R}$

In general, $\Phi$ is large when $R$ is small, and the reverse. In any case, the mortar will have a large compressive resistance due to confinement, since the denominator is small.

\subsection{A new formula for brick blends}

The starting point for the HET formulation is again the compatibility and equilibrium equations of the stack. The solution is developed in a plane strain condition, where mortar and blocks are defined by their thicknesses $t_{m}$ and $t_{b}$, their elastic moduli $E_{m}$ and $E_{b, i}$, and their Poisson's ratios $v_{m}$ and $v_{b, i}$, respectively, with a given combination of volumetric fractions $\rho_{i}$. In particular, concerning a general masonry wall containing randomly blended units, the volumetric fraction of block type $i$ is computed by considering the number of blocks $n_{b, i}$ in the panel with their corresponding thicknesses $t_{b, i}$ over the whole composition of the wall.

$\rho_{i}=\frac{t_{b, i} n_{b, i}}{\sum_{j} t_{b, j} n_{b, j}}$

The equilibrium equation in the horizontal and vertical directions are easily written referring to the mortar and block courses present in the wall:

$\sigma_{h m} t_{m} n_{m}+\sum_{j} \sigma_{h b, j} t_{b, j} n_{b, j}=0, \sigma_{v m}=\sigma_{v b, i}$

A non-dimensional formula is obtained by dividing the horizontal stress by the vertical stress, and each term by the total thickness of the block courses:

$s_{m} k \eta=-\sum_{j} s_{b, j} \rho_{j}$ where $s$ represents the ratio $\sigma_{h} / \sigma_{v}$, and $k \eta$ is the ratio of the mortar thickness to the total block thickness. In practice, $k$ represents the ratio of the number of mortar courses over the number of blocks, while $\eta$ is the ratio of the mortar course average thickness, over the block average thickness.

The horizontal strain of all the materials is defined by the following formula, in which compression and shortening were considered positive:

$\varepsilon_{h}=\frac{1-v^{2}}{E}\left(-\frac{v}{1-v} \sigma_{v}+\sigma_{h}\right)$

The compatibility condition states that the horizontal strain of the mortar and the linked bricks must be the same. By denoting the constrained modulus as $D$, and introducing the non-dimensional stresses $s_{h b, i}$ and $s_{h m}$, the compatibility equations hold:

$$
\begin{aligned}
e_{h m} & =\frac{1}{D_{m}}\left(-\frac{v_{m}}{1-v_{m}}+s_{h m}\right) \\
& =\frac{1}{D_{b, i}}\left(-\frac{v_{b, i}}{1-v_{b, i}}+s_{h b, i}\right)=e_{h b, i}
\end{aligned}
$$

The Eq. (16) encodes the compatibility equation of the horizontal flexibilities $e_{h}$ of the two materials, and can be solved by extracting $s_{h b, i}$ as a function of $s_{h m}$. By substituting all the block nondimensional stresses in Eq. (13), the stress ratio $s_{h m}$ in mortar is computed:

$s_{h m}=\frac{\sigma_{h m}}{\sigma_{v}}=\frac{\sum_{j}\left(\frac{D_{j}}{D_{m}} \frac{v_{m}}{1-v_{m}}-\frac{v_{b, j}}{1-v_{b, j}}\right) \rho_{j}}{k \eta+\sum_{i} \frac{D_{i}}{D_{m}} \rho_{i}}$

Since mortar is considered not involved in the failure process, it is necessary to introduce hypotheses capable to split the horizontal stress resultant of the mortar in the horizontal stresses acting on the different blocks composing the blend. Failure can thus be set either at the lower vertical stress, by producing collapse in the weakest block type, or with a sort of average stress which will bring all the blocks to the limit cracked state at the same time. The first situation can be thought of as a limit elastic brittle one, while the second is a rigid plastic condition. In what follows the two solutions are presented and discussed.

\subsection{Limit elastic brittle condition for a brick blend}

In this case, the block stresses are derived from the mortar stresses by using the relative stiffness $H_{b, i}$ in 
the horizontal direction of the blocks composing the blend. Since:

$\frac{\sigma_{h b, i}}{\varepsilon_{h b, i}}=\frac{E_{b, i} v_{b, i}}{\left(1+v_{b, i}\right)\left(1-2 v_{b, i}\right)}=H_{b, i}$

The mortar stress ratio $s_{h m}$ is split using the different block type stiffness ratios $\mathrm{K}_{b, i}$ computed in terms of the material rigidities $H_{b, i}$ of the blocks and their volumetric fractions $\rho_{i}$ :

$K_{b, i}=\frac{\rho_{i} H_{b, i}}{\sum_{j} \rho_{j} H_{b, j}}$

Then, the failure stress $f_{M \text {,EL }}$ is computed based on the Coulomb formula (3) for all the present block types, and the minimum strength is considered the overall failure stress:

$f_{M, \mathrm{EL}}=\min _{i}\left(\frac{1}{f_{c b, i}}+\frac{s_{h m} k \eta K_{b, i}}{f_{t b, i}}\right)^{-1}$

Thus, for a stack of blended blocks, the forecast elastic stress ratios are $s_{h m}$ for the mortar, and $s_{h m} k \eta$ $K_{b, i}$ for the different block types. The effectiveness of these formulas can be checked against the results of the FEM simulations presented above. In the following Fig. 10 the main results for the CL and CS combinations are presented, by referring to the average of interspersed and clustered patterns.

As is evident from the figures, the stress ratios are in very good agreement over the whole range of volumetric ratios of the studied blends. Indeed, the coefficient of determination $R^{2}$ corresponding to the prediction capability of the proposed formulas shows values higher than 0.95 for quite all the numerical investigations. However, lower values are found dealing with the stresses associated either with limestone blocks or thicker clay bricks in the bricksandstone blends.

\subsection{Limit rigid plastic condition for a brick blend}

If the collapse is postponed till cracks span all over the vertical masonry length, the block blend components are contributing to the final strength based on their respective volumetric ratios, as a sort of strength average. Therefore, the combination formula is obtained from the strength of the various local single block type strengths combined with their shares, so that the wallet strength becomes equal to each component's strength if the volumetric ratio of this component is unity:

$f_{M, \mathrm{PL}}=\left[\sum_{i}\left(\frac{1}{f_{c b, i}}+\frac{s_{h m} k \eta}{f_{t b, i}}\right) \rho_{i}\right]^{-1}$

As will be evident in the comparison with the experiments, the two hypotheses lead to similar results, if the ductility of the system due to the heterogeneity is limited.

\section{Comparison of HET with experimental results}

The proposed formulas were used in the interpretation of the presented experiments. In addition to these formulas, since in the literature the fractional power
Fig. 10 Comparison of the analytical and numerical stress ratios for the ClaySandstone (CS) blends (a) and the Clay-Limestone (CL) blends (b)

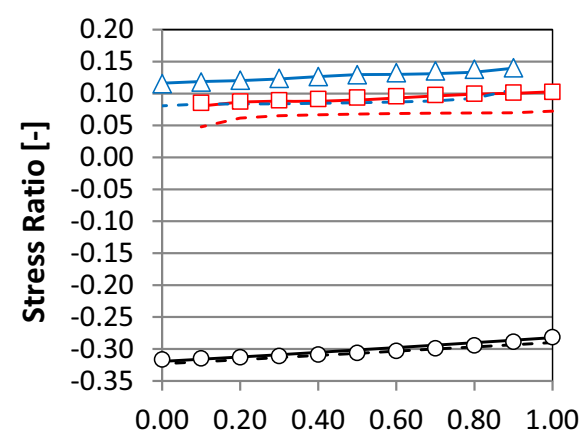

(a) Clay Brick Content [\%]

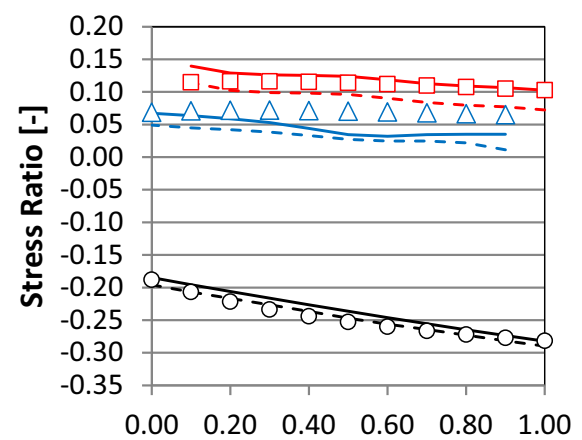

(b)

Clay Brick Content [\%]

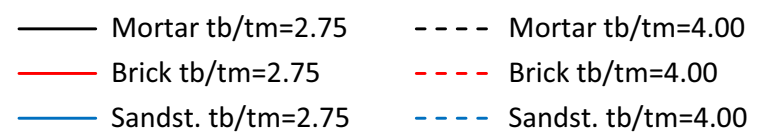

$\bigcirc \quad$ Mortar Analytical
$\square \quad$ Brick Analytical
$\triangle \quad$ Sandstone Analytical 
formula proposed by EC6 [5] is widely used in checking results (see for example Ferretti [4]), an extended EC6 formula never proposed before in the literature, is derived for the case of blended blocks:

$$
\begin{aligned}
f_{M, \mathrm{EC} 6} & =k \cdot f_{c m}^{a} \cdot\left(\sum_{i} \frac{\rho_{i}}{f_{c b, i}}\right)^{-b} \\
& =k \cdot f_{c m}^{a} \cdot\left(\sum_{i} \frac{\rho_{i}}{f_{c b, i}}\right)^{-b}
\end{aligned}
$$

Suitable values for the parameters are $k=0.6 \div 0.7, a=0.25 \div 0.30, b=0.75 \div 0.70$.

The formula (22) is based on the consideration that in a stack of random elastic perfectly plastic blocks which yield approximately at the same strain, the strength can be computed as the average modulus multiplied by the yielding strain, and therefore by the weighted harmonic mean of the strengths of the various components:

$$
\begin{aligned}
f_{b, h} & =\varepsilon_{y} \cdot E_{h}=\varepsilon_{y} \cdot\left(\sum_{i} \frac{\rho_{i}}{E_{b, i}}\right)^{-1} \\
& =\left(\sum_{i} \frac{\rho_{i}}{E_{b, i} \cdot \varepsilon_{y}}\right)^{-1}=\left(\sum_{i} \frac{\rho_{i}}{f_{b, i}}\right)^{-1}
\end{aligned}
$$

(Online Source 2) shows the comparison with the experiments, while Fig. 11 collects all the strength value pairs comparing the performances of the analytical formulas against the experimental outcomes. Although the experiments are very complex, with materials with very different and scattered properties, the agreement of the proposed formulas is considerable, and even the very simple Euro Code 6 power formula proves to be a good evaluation tool. However, it is to mention that a correct evaluation of the data like $f_{t}, \phi, v$ is of paramount importance in

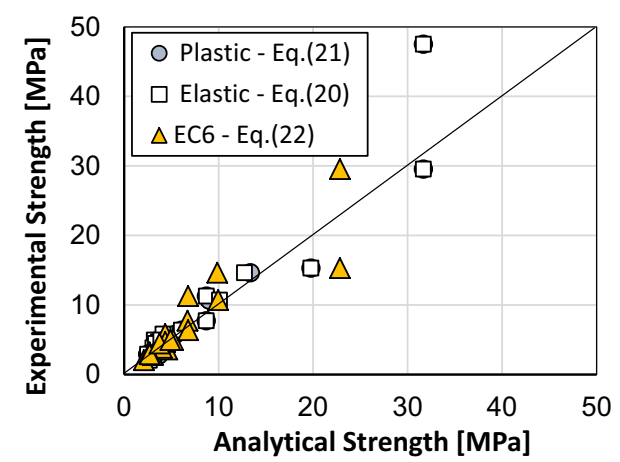

Fig. 11 Model strengths versus experimental strengths in masonry walls (Online Source 2) deriving the mechanical parameters to be used in the proposed formulas. Obviously, when only one type of block is present, plastic and elastic masonry strengths are exactly equal.

\section{Conclusions}

In this study, a systematic procedure, capable of evaluating the compressive strength of masonry wallets with blended blocks, has been presented and checked against available experimental investigations.

Although the procedure is considering the collapse as a limit elastic process ending with the onset of a diffuse cracking in the block blend forming the masonry, the result is a precise strength evaluation, if the mechanical parameters of the materials composing the walls are defined with care.

The mortar-unit interaction problem typical of Haller Hilsdorf theory has been solved as a plane strain equilibrium problem based on a wide numerical investigation.

The importance of material parameters often lacking in experimental studies, namely the tensile strength and the Poisson ratio, has been stressed. Some useful formulas able to fill the gap, allowing the estimation of these values from the uniaxial compressive strength, were reviewed.

From the analysis, it is clear that the heterogeneity due to a dispersed distribution of blocks showing different properties is producing a sort of apparent ductility which comes out in a harmonic averaging of the block strengths. Moreover, the horizontal compressive stress in the mortar layers is mostly depending on the mortar Poisson ratio only, while the horizontal tensile stress in the blocks is even a function of the stiffness ratio of each block type in turn.

A new analytical tool, namely the Hilsdorf Extended Theory (HET) was derived in both the elastic and plastic ranges. A wide experimental investigation on 1:4 scale specimens carried out at the University of Firenze is discussed in detail.

The comparison of the theoretical results with the outcomes of the experimental investigation and the corresponding $R^{2}$ values point out the good predictive capability of both the derived analytical formulas.

A further future step of the theoretical derivation will concern the introduction of the effect of the bonding pattern and the analysis of blended block 
walls with multiple leaves. It is finally to cite that one of the most important and disregarded components of the real walls is the presence of voids, which is rarely investigated although it constitutes a phase with a significant strengthless volume fraction, introducing in this way a consistent capacity reduction.

Acknowledgements The authors want to acknowledge the deep influence of prof. Silvia Briccoli Bati in diffusing the culture of experimental testing for masonry structures. Acting as the Tutor of Daniela Fenocchi and Sara Rosi, she designed and directed more than 20 years ago the experiments, which are used now in checking the new Extended Hilsdorf Theory.

Funding This research did not receive any specific grant from funding agencies in the public, commercial, or not-for-profit sectors.

\section{Declarations}

Conflict of interest The authors declare that they have no known competing financial interests or personal relationships that could have appeared to influence the work reported in this paper.

Open Access This article is licensed under a Creative Commons Attribution 4.0 International License, which permits use, sharing, adaptation, distribution and reproduction in any medium or format, as long as you give appropriate credit to the original author(s) and the source, provide a link to the Creative Commons licence, and indicate if changes were made. The images or other third party material in this article are included in the article's Creative Commons licence, unless indicated otherwise in a credit line to the material. If material is not included in the article's Creative Commons licence and your intended use is not permitted by statutory regulation or exceeds the permitted use, you will need to obtain permission directly from the copyright holder. To view a copy of this licence, visit http://creativecommons.org/licenses/by/4.0/.

\section{References}

1. Lotfi HR, Shing PB (1994) Interface model applied to fracture of masonry structures. J Struct Eng 120:63-80. https://doi.org/10.1061/(ASCE)0733-9445(1994)120:1(63)

2. Lourenço PB, Rots JG (1997) Multisurface interface model for analysis of masonry structures. J Eng Mech 123(7):660-668. https://doi.org/10.1061/(ASCE)07339399(1997)123:7(660)

3. Zucchini A, Lourenço PB (2002) A micro-mechanical model for the homogenisation of masonry. Int J Solids Struct 39:3233-3255

4. Ferretti D (2020) Dimensional analysis and calibration of a power model for compressive strength of solid-clay-brick masonry. Eng Struct 205:110064. https://doi.org/10.1016/j. engstruct.2019.110064
5. CEN (2005) EN 1996-1-1: Eurocode 6: design of masonry structures-Part 1-1: general rules for reinforced and unreinforced masonry structures

6. Proske D, Gelder PV (2009) Masonry strength. In: Proske D (ed) Safety of historical stone arch bridges. Springer, Berlin Heidelberg, pp 165-197

7. Hilsdorf HK (1969) Investigation into the failure mechanism of brick masonry loaded in axial compression. In: Johnson FB (ed) Des Eng Constr Mason Prod. Gulf Publishing, Houston, Texas, pp 34-41

8. Haller P (1958) Hochhausbau in Backstein: die technischen Eigenschaften von Back-stein-Mauerwerk für Hochhäuser. Schweiz Bauztg 76:411-419

9. Aprile A, Benedetti A, Grassucci F (2001) Assessment of cracking and collapse for old brick masonry columns. J Struct Eng 127:1427-1435. https://doi.org/10.1061/ (ASCE)0733-9445(2001)127:12(1427)

10. Como M (2013) Masonry strength and deformability. In: Aita D, Pedemonte O, Williams K (eds) Statics of historic masonry constructions. Springer series in solid and structural mechanics, vol 1. Springer, Berlin, Heidelberg, pp 1-49

11. Mc NS, Abrams DP (1985) Mechanics of masonry in compression. ASCE J Struct Eng 111(4):857-870. https:// doi.org/10.1061/(ASCE)0733-9445(1985)111:4(857)

12. Shrive NG (1985) Compressive strength and strength testing of masonry. In: Proceedings of the 7th IB2MAC, Melbourne, pp 699-710

13. Hayen R, Van Balen K, Van Gemert D (2005) The mechanical behaviour of mortars in triaxial compression. In: Proceedings of the SAHC 2004, Taylor \& Francis, Padova, pp 611-618, ISBN 0415363799

14. Gabet T, Malécot Y, Daudeville L (2008) Triaxial behaviour of concrete under high stresses: influence of the loading path on compaction and limit states. Cem Concr Res 38:403-412. https://doi.org/10.1016/j.cemconres.2007.09. 029

15. Kohees M, Sanjayan J, Rajeev P (2019) Stress-strain relationship of cement mortar under triaxial compression. Constr Build Mater 220:456-463. https://doi.org/10.1016/j. conbuildmat.2019.05.146

16. Drougkas A, Verstrynge E, Hayen R, Van Balen K (2019) The confinement of mortar in masonry under compression: experimental data and micro-mechanical analysis. Int $\mathrm{J}$ Solids Struct 162:105-120. https://doi.org/10.1016/j. ijsolstr.2018.12.006

17. Benedetti A, Spinelli P (1999) On the strength uncertainty assessment of masonry walls made with non-homogeneous brick mixtures. In: Schueller P, Kafka GI (eds) Safety and reliability. Balkema, Rotterdam, pp 525-530

18. Finocchio D (2001) Comportamento meccanico di pannelli murari eterogenei. Graduation thesis, University of Florence (in Italian)

19. Rosi S (2002) Pannelli murari eterogenei: modelli di comportamento meccanico, Graduation thesis, University of Florence (in Italian)

20. Anthoine A (1997) Homogenization of periodic masonry: plane stress, generalized plane strain, or 3D modelling? Commun Numer Methods Eng 13:319-326. https://doi.org/ 10.1002/(SICI)1099-0887(199705)13:5\%3c319::AIDCNM55\%3e3.0.CO;2-S 
21. Chen WF, Han DJ (1988) Plasticity for structural engineers, Springer-Verlag New York Inc, USA. ISBN 9781932159752

22. Li D, Wong LNY (2013) The Brazilian disc test for rock mechanics applications: review and new insights. Rock Mech Rock Eng 46:269-287. https://doi.org/10.1007/ s00603-012-0257-7

23. Arioglu N, Canan GZ, Arioglu E (2006) Evaluation of ratio between splitting tensile strength and compressive strength for concretes up to $120 \mathrm{MPa}$ and its application in strength criterion. ACI Mater J 103(1):18-24. https://doi.org/10. $14359 / 15123$

24. Chen X, Wu S, Zhou J (2014) Strength values of cementitious materials in bending and tension test methods. J Mater Civ Eng 26(3):484-490. https://doi.org/10.1061/ (ASCE)MT.1943-5533.0000846

25. Singh SB, Munjal P, Thammishetti N (2015) Role of water/ cement ratio on strength development of cement mortar. J Build Eng 4:94-100. https://doi.org/10.1016/j.jobe.2015. 09.003

26. DICAM (2010) Relazione tecnica d'interpretazione dei materiali presenti nel palazzo comunale di Forlì (in Italian). LISG Laboratory report, DICAM Department, University of Bologna, Italy

27. Vasarhelyi B (2009) A possible method for estimating the Poisson's rate values of the rock masses. Acta Geod Geophys Hung 44(3):313-322. https://doi.org/10.1556/AGeod. 44.2009.3.4

28. Zhang N, Sheng Z, Li X, Li S, He J (2011) Study of relationship between Poisson's ratio and angle of internal friction for rocks. Chin J Rock Mech Eng 30(1):2599-2609 (in Chinese)

29. Lógó BA, Vásárhelyi B (2019) Estimation of the Poisson's rate of the intact rock in the function of the rigidity. Period Polytech Civ Eng 63(4):1030-1037. https://doi.org/10. 3311/PPci.14946

30. Cai M (2010) Practical estimates of tensile strength and Hoek-Brown strength parameter $m_{i}$ of brittle rocks. Rock Mech Rock Eng 43:167-184. https://doi.org/10.1007/ s00603-009-0053-1

31. Anson M, Newman K (1966) The effect of mix proportions and method of testing on Poisson's ratio for mortars and concretes. Mag Concr Res 18:115-130. https://doi.org/10. 1680/MACR.1966.18.56.115

32. Mohamad G, Fonseca FS, Vermeltfoort AT, Lubeck A (2018) Stiffness plasticity degradation of masonry mortar under compression: preliminar results. Rev IBRACON Estrut Mater 11(2):279-295. https://doi.org/10.1590/s19834195201800020004

33. Mohamad G, Lourenço PB, Roman HR, Rizzatti E, Sartori $\mathrm{T}$ (2012) Poisson of bedding mortar under multi-axial stress conditions. In: Fifteenth international brick block masonry conference

34. Rahman A, Ueda T (2014) Experimental investigation and numerical modeling of peak shear stress of brick masonry mortar joint under compression. J Mater Civ Eng 26(9):04014061

35. Rajabi AM, Moaf O, Farzam, (2017) Simple empirical formula to estimate the main geomechanical parameters of preplaced aggregate concrete and conventional concrete. Constr Build Mater 146:485-492
36. Barragán BE, Giaccio G, Zerbino R (2001) Fracture and failure of thermally damaged concrete under tensile loading. Mater Struct 34:312-319. https://doi.org/10.1007/BF02482211

37. Augenti N, Parisi F, Acconcia E (2012) MADA: online experimental database for mechanical modelling of existing masonry assemblages. In: Fifteenth world conference on earthquake engineering

38. Pelà L, Roca P, Benedetti A (2016) Mechanical characterization of historical masonry by core drilling and testing of cylindrical samples. Int J Archit Herit 10:360-374. https:// doi.org/10.1080/15583058.2015.1077906

39. Pelà L, Canella E, Aprile A, Roca P (2016) Compression test of masonry core samples extracted from existing brickwork. Constr Build Mater 119:230-240. https://doi. org/10.1016/j.conbuildmat.2016.05.057

40. Segura J, Pelà L, Roca P, Cabané A (2019) Experimental analysis of the size effect on the compressive behaviour of cylindrical samples core-drilled from existing brick masonry. Constr Build Mater 228:116759. https://doi.org/ 10.1016/j.conbuildmat.2019.116759

41. Mohammed A, Hughes TG, Mustapha A (2011) The effect of scale on the structural behaviour of masonry under compression. Constr Build Mater 25:303-307

42. Thamboo JA, Dhanasekar M (2019) Correlation between the performance of solid masonry prisms and wallets under compression. J Build Eng 22:429-438. https://doi.org/10. 1016/j.jobe.2019.01.007

43. Drougkas A, Roca P, Molins C (2015) Numerical prediction of the behavior, strength and elasticity of masonry in compression. Eng Struct 90:15-28. https://doi.org/10.1016/j. engstruct.2015.02.011

44. Boffill Y, Blanco H, Lombillo I, Villegas L (2019) Assessment of historic brickwork under compression and comparison with available equations. Constr Build Mater 207:258-272. https:// doi.org/10.1016/j.conbuildmat.2019.02.083

45. Binda L, Pina-Henriques J, Anzani A, Fontana A, Lourenço PB (2006) A contribution for the understanding of loadtransfer mechanisms in multi-leaf masonry walls: testing and modelling. Eng Struct 28:1132-1148. https://doi.org/ 10.1016/j.engstruct.2005.12.004

46. Meimaroglou N, Mouzakis H (2018) Mechanical properties of three-leaf masonry walls constructed with natural stones and mud mortar. Eng Struct 172:869-876. https://doi.org/ 10.1016/j.engstruct.2018.06.015

47. Lumantarna R, Biggs DT, Ingham JM (2014) Uniaxial compressive strength and stiffness of field-extracted and laboratory-constructed masonry prisms. J Mater Civ Eng 26(4):567-575. https://doi.org/10.1061/(ASCE)MT.19435533.0000731

48. Al-Ajmi AM, Zimmerman RW (2005) Relation between the Mogi and the Coulomb failure criteria. Int J Rock Mech Min Sci 42:431-439. https://doi.org/10.1016/j.ijrmms.2004.11. 004

49. Chang C, Haimson B (2012) A failure criterion for rocks based on true triaxial testing. Rock Mech Rock Eng 45:1007-1010. https://doi.org/10.1007/s00603-012-0280-8

Publisher's Note Springer Nature remains neutral with regard to jurisdictional claims in published maps and institutional affiliations. 